\title{
CASOS INVESTIGATIVOS PARA A PROMOÇÃO DA CSCL NO ENSINO SUPERIOR DE QUÍMICA
}

\author{
Patrícia Fernanda de Oliveira Cabral, Nilcimar dos Santos Souza ${ }^{\#}$ e Salete Linhares Queiroz* \\ Departamento de Físico-Química, Instituto de Química de São Carlos, Universidade de São Paulo, 13566-590, São Carlos - SP, Brasil
}

Recebido em 27/02/2017; aceito em 03/05/2017; publicado na web em 11/07/2017

\begin{abstract}
INVESTIGATIVE CASE STUDIES FOR THE PROMOTION OF CSCL IN UNDERGRADUATE CHEMISTRY TEACHING. This paper addresses a didactic activity based on computer-supported collaborative learning (CSCL) principles applied to a scientific communication course offered to undergraduate chemistry students. We investigated the dynamics of interactions among the students within the groups focusing on skills of conversation described in the Collaborative Learning Model developed by Soller et al. In a virtual learning environment named eduqui.info students solved investigative case studies related to environmental pollution caused by plastic and oil, replacement of aviation gasoline by ethanol and replacement of trans fat found in foods. The messages posted on eduqui.info Forum were analyzed for the identification of the students' collaboration effectiveness. The major subskills related to Collaborative Learning Model found in the students' messages were inform, argue and request. Activities like the one addressed in this study can help undergraduate chemistry students to learn and apply core scientific concepts and skills.
\end{abstract}

Keywords: case studies; chemistry; higher education; eduqui.info.

\section{INTRODUÇÃO}

No que concerne às novas abordagens que envolvem o uso de Tecnologias de Informação e Comunicação (TIC) em sala de aula, a Aprendizagem Colaborativa com Suporte Computacional, em língua inglesa Computer-Supported Collaborative Learning (CSCL), visa o desenvolvimento de sistemas computacionais potencialmente capazes de propiciar a realização de atividades que estimulem a criatividade, a exploração intelectual e a interação social em grupo. ${ }^{1}$

O termo CSCL foi utilizado publicamente pela primeira vez em um seminário internacional em 1989, na Itália, e a primeira conferência internacional bianual sobre o assunto ocorreu em 1995, nos Estados Unidos. Outra iniciativa que impulsionou a divulgação dos trabalhos sobre a temática foi a criação, em 2006, do International Journal of Computer-Supported Collaborative Learning. ${ }^{2}$

As origens da CSCL repousam no desenvolvimento de 3 projetos, todos idealizados com o objetivo comum de orientar a educação à constituição de significado, a partir do emprego das TIC, com a incorporação de novas formas de atividade social na instrução. ${ }^{1}$ O Eletronic Networks for Interaction (ENFI), da Universidade de Gallaudet (EUA), buscou auxiliar o desenvolvimento da escrita por alunos surdos ou com pouca audição; o Computer-Supported Intentional Learning Environment (CSILE), da Universidade de Toronto (Canadá), buscou o estímulo à escrita dos alunos; o Fifth Dimension, da Universidade da Califórnia em San Diego (EUA), buscou melhorar a habilidade de escrita e de resolução de problemas dos estudantes. ${ }^{1}$

Pesquisas relacionadas à CSCL têm sido reportadas na literatura ao longo dos últimos anos e apontam que os avanços tecnológicos e a criação de ferramentas de interação social permitem que os estudantes se conectem de forma síncrona ou assíncrona, o que coloca a CSCL em integração com o ambiente educacional, validando a sua importância e expansão. ${ }^{3,4}$

Atividades pautadas na CSCL podem ser aplicadas a todos os níveis da educação formal e na educação informal e têm como vantagens a melhora da qualidade das soluções para problemas propostos

*e-mail: salete@iqsc.usp.br

\#Docente da Universidade Federal do Rio de Janeiro, campus de Macaé pelo professor; o compartilhamento dos resultados de pesquisa entre os membros do grupo; a exposição de várias perspectivas e interpretações; a promoção da argumentação; a construção social do conhecimento e a mudança conceitual do indivíduo; diversos tipos de comunicação (aluno-aluno; aluno-professor; professor-aluno). ${ }^{2}$

Partindo desse pressuposto, neste trabalho de caráter exploratório temos como objetivo descrever uma atividade didática pautada em interações colaborativas estabelecidas entre estudantes de graduação em Química em um Ambiente Virtual de Aprendizagem (AVA), denominando eduqui.info, desenvolvido no âmbito do Grupo de Pesquisa em Ensino de Química do IQSC (GPEQSC), com o apoio da Fundação de Amparo à Pesquisa do Estado de São Paulo (FAPESP), no qual os estudantes interagiram por meio da ferramenta Fórum em busca da melhor solução para casos investigativos de forma colaborativa. A análise das interações foi realizada com base no Modelo de Aprendizagem Colaborativa, sucintamente descrito a seguir, com o intuito de investigarmos a efetividade da colaboração por meio do desenvolvimento de habilidades de comunicação. Dessa forma, pretendemos contribuir para a evolução de estudos que envolvam a CSCL a partir da investigação das interações entre os estudantes, considerando estas como um processo social, no qual há o compartilhamento de informações, a promoção de atitudes relacionadas ao respeito e à valorização das opiniões dos colegas e a divisão da responsabilidade sobre o aprendizado. ${ }^{5}$

\section{Modelo de Aprendizagem Colaborativa}

Proposto por Soller et al., ${ }^{6}$ o Modelo de Aprendizagem Colaborativa tem como propósito a identificação dos grupos que apresentam aprendizagem colaborativa efetiva. Para tanto, 5 indicadores foram concebidos como descritores das características inerentes à interação de tais grupos: participação, habilidades interpessoais, habilidades de comunicação, processamento grupal e interdependência positiva.

Neste trabalho, as interações estabelecidas entre os alunos serão discutidas com relação ao indicador habilidades de comunicação, visto que na medida em que a comunicação efetiva é desenvolvida nos pequenos grupos, os estudantes tornam-se capazes de incentivar os demais membros a lançar questionamentos, explicar e justificar 
suas opiniões, além de articular seu raciocínio, elaborar e refletir sobre seus conhecimentos, o que pode motivar e maximizar a aprendizagem. Além disso, os estudantes mostram-se capazes de reconhecer os momentos nos quais devem fazer questionamentos, partilhar informações e apresentar comportamentos motivacionais à sua equipe, além de representarem o papel de facilitadores de uma conversa, sabendo como se portar diante de opiniões conflitantes. ${ }^{5}$

Partindo desse pressuposto, Soller et al. ${ }^{6}$ elaboraram a Taxonomia de Habilidades de Aprendizagem Colaborativa, ilustrada na Figura 1 , a fim de identificar as habilidades de comunicação mais recorrentes utilizadas pelos estudantes durante uma atividade colaborativa de resolução de problemas. A partir do Modelo de Aprendizagem Colaborativa, os autores consideram que os grupos que colaboram de forma mais efetiva são aqueles que concentram a sua discussão na habilidade de Aprendizagem Ativa, apresentando as características a ela relacionadas descritas na Figura 1.

A Taxonomia está dividida em 3 níveis de aprofundamento. No primeiro, encontram-se as habilidades de comunicação Conflito Criativo, Aprendizagem Ativa e Conversação. Cada habilidade apresenta sub-habilidades associadas, como Solicitação, Reconhecimento e Manutenção. Cada sub-habilidade apresenta características como Solicitação de Opinião, Apreciação e Resumo de Informações (na Figura 1 são fornecidas ainda frases que exemplificam cada uma das características).

Destacamos que os autores do presente trabalho adicionaram 3 das 39 características apresentadas na Figura 1 (Reafirmação, Citação Direta e Indicação de Referência Bibliográfica), como adaptação à Taxonomia, em vista da natureza de mensagens analisadas que não foram contempladas pelo referido Modelo.

A Tabela 1 apresenta uma breve descrição das sub-habilidades ilustradas na Figura 1.

Destacamos que no trabalho de Soller et al. ${ }^{6}$ os estudantes trabalharam em um AVA programado por Inteligência Artificial e deveriam utilizar frases prontas, expostas como exemplo na Figura 1, para iniciar uma sentença, como "Você poderia, por favor", referente à Sugestão de Ação e "Para resumir", referente ao Resumo de Informações. Em contraponto, neste trabalho não foram utilizados indicadores de sentenças. Tomamos como unidade de análise a

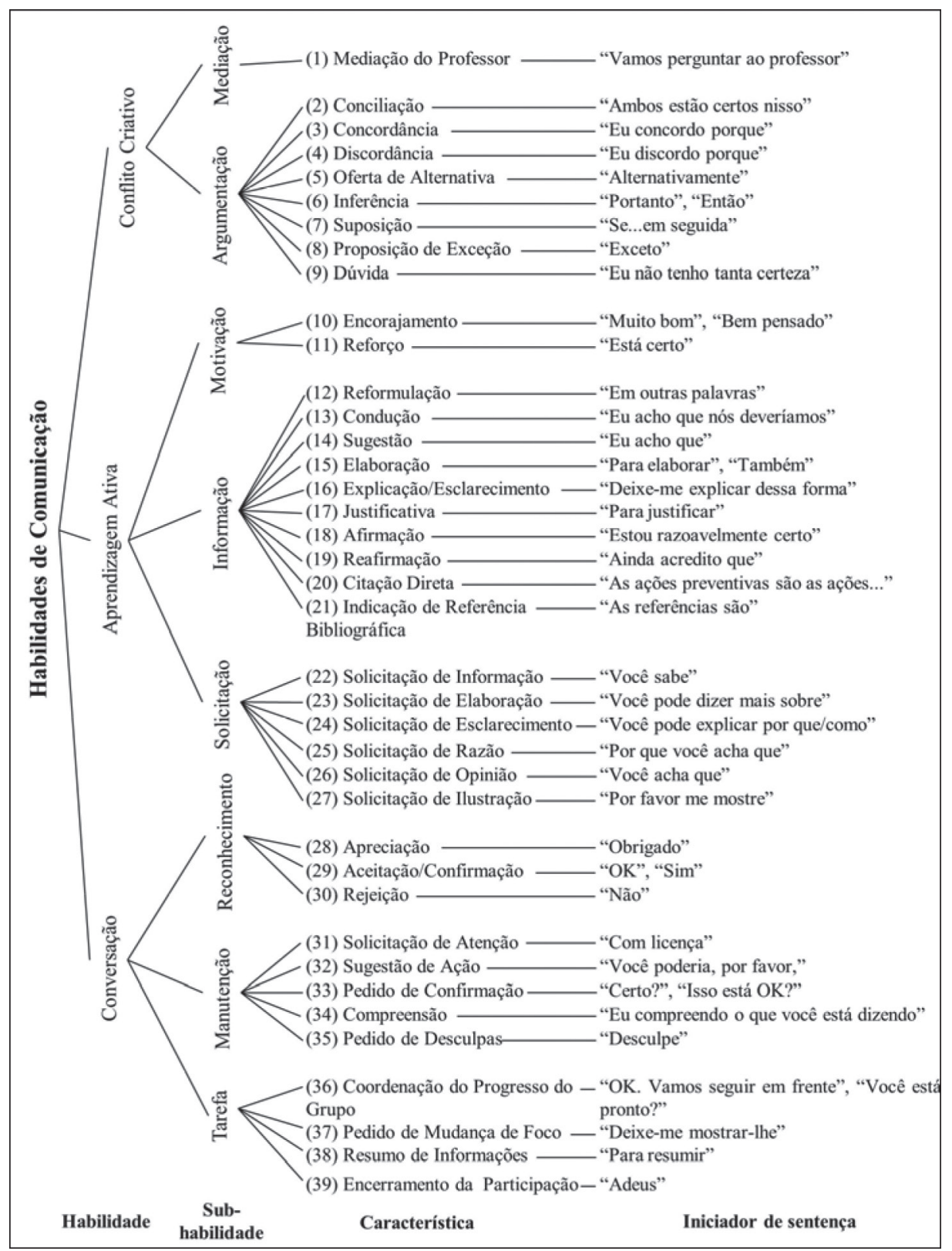

Figura 1. Taxonomia de Habilidades de Aprendizagem Colaborativa (adaptado de Soller et al. $)^{6}$ 
Tabela 1. Descrição das sub-habilidades pertencentes à Taxonomia de Aprendizagem Colaborativa

\begin{tabular}{ll}
\hline \multirow{2}{*}{ Conflito Criativo } & $\begin{array}{l}\text { Argumentação: explicitar julgamento (positivo ou nega- } \\
\text { tivo) acerca dos comentários ou sugestões dos colegas }\end{array}$ \\
\cline { 2 - 3 } Aprendizagem & $\begin{array}{l}\text { Mediação: propor o questionamento ao professor sobre } \\
\text { determinada dúvida }\end{array}$ \\
\hline & $\begin{array}{l}\text { Solicitação: requisitar ajuda/conselhos para solucionar } \\
\text { o problema ou para entender o comentário feito por um }\end{array}$ \\
\hline & $\begin{array}{l}\text { Informação: conduzir ou prosseguir na conversa, ofere- } \\
\text { cendo informações ou conselhos }\end{array}$ \\
\hline Motivação: gerar feedback positivo e reforço \\
\hline $\begin{array}{l}\text { Tarefa: modificar o foco do grupo para uma nova subtarefa } \\
\text { ou ferramenta }\end{array}$ \\
$\begin{array}{l}\text { Manutenção: dar suporte à coesão do grupo e à partici- } \\
\text { pação dos colegas }\end{array}$ \\
$\begin{array}{l}\text { Reconhecimento: informar aos colegas que comentários } \\
\text { foram lidos e apreciados. Responder perguntas com sim/ } \\
\text { não }\end{array}$ \\
\hline
\end{tabular}

exposição de uma ideia, com o intuito de ampliarmos a classificação, analisando a mensagem como um todo.

\section{ATIVIDADE DIDÁTICA: CONTEXTO E APLICAÇÃO}

A atividade didática foi aplicada a 37 graduandos, matriculados no segundo semestre do curso de Bacharelado em Química do Instituto de Química de São Carlos (IQSC) da Universidade de São Paulo, na disciplina Comunicação e Expressão em Linguagem Científica II (teórica, 3 créditos), semestral, de caráter obrigatório. A disciplina tem como objetivo desenvolver as capacidades de leitura, escrita e comunicação oral dos estudantes e não conteúdos específicos de Química. Nessa perspectiva, a aplicação da atividade está alinhada com os objetivos da disciplina.

Os alunos foram divididos em pequenos grupos e solicitados a resolver um dos 4 casos investigativos inseridos no eduqui.info. Uma das ferramentas de escrita do AVA, o Fórum (interação assíncrona), foi utilizada pelos alunos, além de diversas outras ferramentas que auxiliaram os envolvidos no processo ao longo das atividades didáticas.

Os casos, de autoria de membros do GPEQSC, são apresentados na íntegra no Material Suplementar (Quadros 1S a 4S), conforme os apontamentos de Herreid et al., ${ }^{7}$ acerca da elaboração de um "bom caso". Um breve resumo de cada um deles consta a seguir:

Idade do plástico (IP): narrativa sobre 2 estudantes de Química que debatem acerca dos benefícios e malefícios do plástico, em vista do seu uso abundante nessa geração e chegam à conclusão que devem investigar alternativas às embalagens de poli(tereftalato de etileno), comumente denominadas PET. Os alunos são inseridos na narrativa como colegas dos personagens e devem apresentar soluções para o problema e argumentar a favor de uma delas.

Cana-de-açúcar pelos ares (CA): narrativa sobre um empresário do ramo da aviação, dono de uma grande frota de aviões e seu primo, que é químico. $\mathrm{O}$ dono das aeronaves enfrenta problemas devido à crise econômica e durante uma conversa de bar com o primo, surge a ideia de abastecimento das aeronaves com etanol. A partir disso, o primo resolve pesquisar se combustíveis derivados da cana-de-açúcar seriam viáveis. Os alunos são inseridos na narrativa como integrantes de um grupo de pesquisa sobre biodiesel e devem propor soluções para o abastecimento das aeronaves com combustíveis derivados da cana-de-açúcar e argumentar a favor de uma delas.

De galão em galão, a prainha vai para o ralo $(D G)$ : narrativa sobre um pescador, residente na cidade de Macaé - RJ, que relata ao seu filho, que é químico, as mudanças ocorridas na cidade com o passar dos anos, após o início da exploração de petróleo na região. Devido ao crescimento rápido e aos vazamentos de petróleo intrínsecos ao processo de exploração, a cidade aumentou os níveis de poluição, tanto por esgoto quanto por derramamento de petróleo, o que, dentre outras consequências, tornou a área inutilizável pelos moradores. Os estudantes são inseridos na história como químicos da empresa contratada para reduzir o problema e devem propor soluções para que em caso de vazamento de petróleo, as consequências sejam minimizadas e argumentar a favor de uma delas.

Socorro, eu não quero alface! (SA): narrativa sobre a história de uma personagem acima do peso, cliente de uma loja de doces caseiros, cuja dona é sua conhecida. Após um diálogo entre as personagens, a dona da loja manifesta interesse em mensurar a gordura trans utilizada na fabricação de seus biscoitos e também procurar opções para substituí-la durante o processo de expansão dos seus negócios. Os alunos são inseridos na narrativa como amigos do filho da dona da loja, que é estudante de Química e devem indicar formas de substituição da gordura trans dos produtos e argumentar a favor de uma delas.

A divisão dos grupos por estudo de caso está ilustrada na Tabela 2.

Nos 4 grupos, inicialmente, cada aluno fez a leitura individual do estudo de caso, indicou ao menos 2 soluções e argumentou a favor de uma delas (fase 1). A partir dos textos individuais, o docente responsável formou duplas que indicaram soluções distintas para um mesmo caso, a fim de fomentar a discussão entre os alunos no Fórum do eduqui.info. Cada aluno defendeu sua solução com argumentos e contra-argumentou a solução do colega, até o alcance de uma solução colaborativa (fase 2). A partir da solução conjunta, cada dupla escreveu um texto colaborativo (fase 3). No presente trabalho são analisadas as mensagens geradas na fase 2 . Devido ao grande volume de dados coletados, selecionamos 2 duplas referentes a cada estudo de caso, sendo a mais e a menos participativa durante as atividades propostas. As mensagens foram classificadas de acordo com as habilidades de Conflito Criativo (CC), Aprendizagem Ativa (AA) e Conversação (C), conforme o Modelo de Aprendizagem Colaborativa. Para tanto, de acordo com a Figura 1, as características foram enumeradas de 1 a 39. A título de exemplo das discussões ocorridas no eduqui.info e da maneira com que se procedeu a análise, a Tabela 3 ilustra trechos da discussão da dupla IP1, bem como sua classificação.

\section{RESULTADOS E DISCUSSÃO}

A análise se deu por meio da Taxonomia de Habilidades de Aprendizagem Colaborativa, proposta por Soller et al. ${ }^{6}$ conforme mencionado anteriormente, a fim de investigar a dimensão das

Tabela 2. Distribuição dos 37 alunos em grupos e seus respectivos estudos de caso

\begin{tabular}{lcccc}
\hline & GRUPO 1 & GRUPO 2 & GRUPO 3 & GRUPO 4 \\
\hline Número de integrantes & 9 & 10 & 10 & 8 \\
\hline Estudo de caso recebido & Idade do plástico & Cana-de-açúcar pelos ares & $\begin{array}{c}\text { De galão em galão, a prainha } \\
\text { vai para o ralo }\end{array}$ & \begin{tabular}{c} 
Socorro, eu não quero alface! \\
\hline
\end{tabular} \\
\hline
\end{tabular}


Tabela 3. Exemplo de análise de um trecho da discussão dos alunos no Fórum do eduqui.info

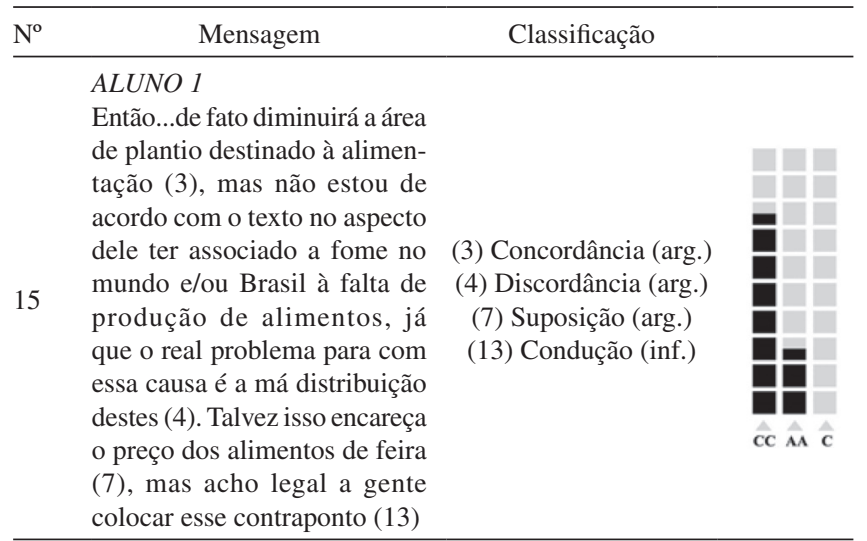

\section{ALUNO 2}

Também concordo com isso

16 (3). Mas a bactéria precisa da cana inteira ou só do bagaço? Não entendi direito essa parte (24)
(3) Concordância (arg.) (24) Solicitação de esclarecimento (sol.)

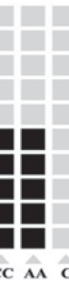

habilidades de comunicação ocorridas durante a interação dos estudantes no Fórum do eduqui.info para a resolução dos casos investigativos. De acordo com os autores, esta análise pode oferecer subsídios para a investigação da efetividade da colaboração dos pequenos grupos. Tendo em vista o exposto, apresentamos a seguir o resultado para 8 duplas, 2 para cada estudo de caso, e em seguida, uma análise comparativa entre as mesmas.

\section{Idade do plástico}

De acordo com os critérios pré-estabelecidos, analisamos as discussões das duplas IP1 e IP3. Estas foram a mais e a menos participativa em número de mensagens trocadas no Fórum durante a atividade, respectivamente. Nesse estudo de caso, os estudantes deveriam indicar alternativas ao uso das embalagens PET. Na solução textual inicial e individual dos 4 alunos que resolveram este caso, 1 aluno escolheu como melhor solução a substituição das embalagens de PET por embalagens biodegradáveis à base de biomassa, evidenciando aspectos ambientais, como a substituição do petróleo, que é uma fonte de energia não-renovável, aspectos científicos e econômicos, por se tratar de um processo vantajoso de eliminação de resíduos, barato e eficaz, que embora seja mais caro do que o plástico produzido pelo petróleo, por meio de pesquisas pode ser melhorado e implantado no futuro.

Outros 2 alunos optaram pela manutenção do uso das embalagens PET aliada à reciclagem e 1 deles enfatizou a necessidade de coleta seletiva e conscientização da população. Nos textos foram evidenciados aspectos ambientais, como a diminuição da poluição e o tempo necessário para a degradação do plástico, aspectos sociais, referentes à conscientização da população, e aspectos econômicos, pela citação de que o Brasil deixa de economizar 6 bilhões de reais ao ano e o aumento da renda de famílias que fazem a coleta do material reciclável.

O último aluno indicou como melhor solução para o estudo de caso a criação de uma lei para a regulamentação do uso de plástico na indústria, de modo que as empresas sejam obrigadas a utilizar uma percentagem pré-estabelecida de plástico reciclado ou biodegradável. Foram evidenciados aspectos políticos relacionados à criação da lei, aspectos sociais, referentes a propagandas que poderiam ser pagas pelas empresas a fim de conscientizar a população, e aspectos econômicos, pois as indústrias manteriam a mesma competitividade em relação ao uso do plástico. Finalizada a etapa de trabalho individual, as 2 duplas formadas produziram 35 mensagens no Fórum, uma média de 17,5 mensagens por dupla. A Tabela 4 apresenta, para cada dupla, como os diversos posicionamentos e abordagens individuais de seus integrantes foram confrontados nos grupos e o total de mensagens produzidas em cada discussão.

Tabela 4. Solução inicial proposta por cada membro dos grupos para o estudo de caso Idade do plástico

\begin{tabular}{lccc}
\hline Grupo & \multicolumn{2}{c}{ Soluções } & $\begin{array}{c}\text { Total de } \\
\text { Mensagens }\end{array}$ \\
\cline { 2 - 3 } IP1 & $\begin{array}{c}\text { Mluno 1 } \\
\text { Manutenção do uso de } \\
\text { embalagens PET aliada } \\
\text { à reciclagem }\end{array}$ & $\begin{array}{c}\text { Criação de uma lei } \\
\text { para que as indústrias } \\
\text { utilizem uma porcenta- } \\
\text { gem pré-estabelecida } \\
\text { de plástico reciclável ou } \\
\text { biodegradável }\end{array}$ \\
\hline IP3 & $\begin{array}{c}\text { Manutenção do uso de } \\
\text { embalagens PET aliada } \\
\text { à reciclagem }\end{array}$ & $\begin{array}{c}\text { Substituição das embala- } \\
\text { gens PET por embala- } \\
\text { gens biodegradáveis à } \\
\text { base de biomassa }\end{array}$ \\
\hline
\end{tabular}

Nas discussões, os alunos consideraram fortemente os aspectos ambientais e econômicos supracitados envolvidos na substituição das embalagens PET. Além disso, mensuraram a viabilidade técnica dos processos industriais e a escolha da matéria-prima. Dessa forma, foram indicados os pontos de concordância e discordância no texto dos colegas, em defesa do ponto de vista próprio, por meio de argumentos apoiados em referências bibliográficas. Assim, IP1 assumiu que a melhor solução para o caso é a substituição por plástico biodegradável de açúcar aliada à implantação de lei que propõe o uso de uma percentagem desse plástico pelas indústrias. Já IP3 considerou que a manutenção das embalagens PET aliada à reciclagem é a melhor solução para o estudo de caso.

A Figura 2 apresenta o percentual das mensagens classificadas de acordo com a Taxonomia de Habilidades de Aprendizagem Colaborativa em seus 3 níveis de aprofundamento. Cabe destacar que apenas as características evidenciadas durante a discussão das duplas são ilustradas no gráfico e a numeração apresentada no eixo horizontal corresponde à apresentada na Figura 1. Nessa perspectiva, não consta na Figura 2 a indicação das 39 características elencadas na Figura 1.

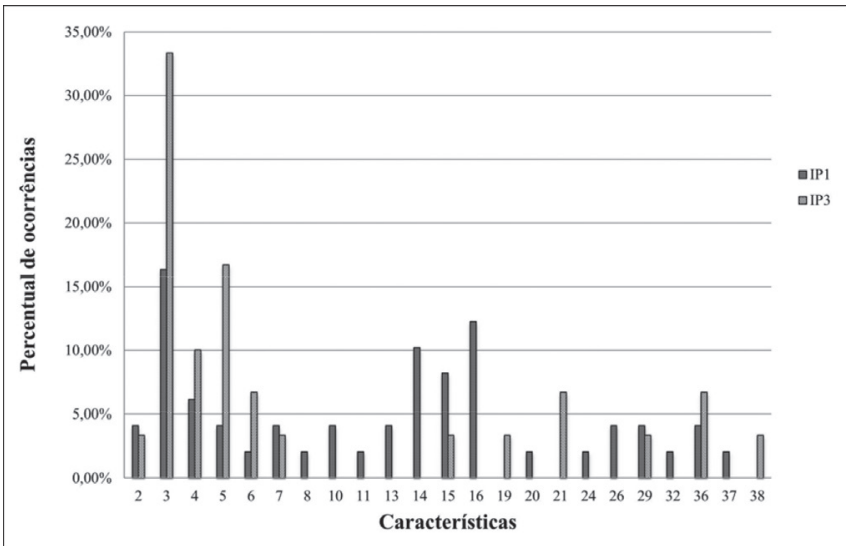

Figura 2. Percentual de mensagens classificadas de acordo com as características expostas na Taxonomia de Habilidades de Aprendizagem Colaborativa para o caso Idade do plástico 
A Figura 2 indica a ocorrência de 23 características de comunicação possíveis, sendo que a dupla IP1 fez uso de 20 características, enquanto a dupla IP3 fez uso de apenas 12 características. A análise qualitativa de tais resultados em comparação com os demais casos investigativos será evidenciada no tópico Efetividade da colaboração durante a resolução dos estudos de caso: uma análise comparativa. Devido à limitação de espaço, os gráficos com o percentual de mensagens classificadas para os demais casos investigativos podem ser consultados no Material Suplementar.

\section{Cana-de-açúcar pelos ares}

De acordo com os critérios pré-estabelecidos, analisamos as discussões das duplas CA1 (mais participativa) e CA5 (menos participativa). Nesse estudo de caso, os estudantes deveriam indicar qual o melhor combustível à base de cana-de-açúcar para substituir a gasolina de aviação no abastecimento de uma frota de aviões. $\mathrm{Na}$ solução textual inicial e individual dos 4 alunos que resolveram o caso, 1 aluno escolheu como melhor solução a substituição das aeronaves convencionais por uma nova frota com tanques de combustível flex. Na produção textual desse aluno foram destacados aspectos econômicos, pois o dono da frota poderia escolher o combustível que oferece o maior custo-benefício em determinado momento, aspectos científicos, relacionados à maior eficiência e potência do motor, e aspectos ambientais, pois a poluição gerada pela queima do etanol seria menor.

Outros 2 alunos optaram pelo uso do etanol e um deles enfatizou a necessidade de modificação nos tanques das aeronaves para a compatibilidade do combustível. Foram evidenciados aspectos ambientais, referentes à maior sustentabilidade e menor poluição atribuídas ao uso do etanol, aspectos econômicos, visto que a produção de etanol é mais barata do que a de combustíveis provenientes do petróleo. Além disso, os estudantes ressaltaram que o uso desse combustível deve se restringir a aviões de pequeno porte, justificado por aspectos científicos, uma vez que o combustível não pode ser utilizado em altitudes elevadas, devido à sua baixa densidade energética, por exemplo.

$\mathrm{O}$ último aluno indicou como melhor solução para o estudo de caso a substituição da gasolina de aviação por um biocombustível produzido pela fermentação da sacarose da cana-de-açúcar e elencou aspectos econômicos, como a facilidade e baixo preço de produção do biocombustível e aspectos ambientais, relacionados ao menor custo na produção. Finalizada a etapa de trabalho individual, as 2 duplas formadas produziram 26 mensagens no Fórum, uma média de 13 mensagens por dupla. A Tabela 5 apresenta, para cada dupla, como os diversos posicionamentos e abordagens individuais de seus integrantes foram confrontados nos grupos e o total de mensagens produzidas em cada discussão.

Tabela 5. Solução inicial proposta por cada membro dos grupos para o estudo de caso Cana-de-açúcar pelos ares

\begin{tabular}{cccc}
\hline \multirow{2}{*}{ Grupo } & \multicolumn{2}{c}{ Soluções } & $\begin{array}{c}\text { Total de } \\
\text { Mensagens }\end{array}$ \\
\cline { 2 - 3 } & $\begin{array}{c}\text { Substituição da gasolina } \\
\text { de aviação no abaste- } \\
\text { cimento das aeronaves } \\
\text { por um biocombustível } \\
\text { produzido a partir da } \\
\text { fermentação da sacarose } \\
\text { da cana-de-açúcar }\end{array}$ & $\begin{array}{c}\text { Substituição da } \\
\text { gasolina de aviação } \\
\text { no abastecimento das } \\
\text { aeronaves por etanol }\end{array}$ & \multirow{2}{*}{14} \\
\hline \multirow{4}{*}{ CA5 } & $\begin{array}{c}\text { Substituição da frota de } \\
\text { aeronaves por outra com } \\
\text { tanques de combustível } \\
\text { flex. }\end{array}$ & $\begin{array}{c}\text { Substituição da } \\
\text { gasolina de aviação } \\
\text { no abastecimento das } \\
\text { aeronaves por etanol }\end{array}$ & \multirow{2}{1}{12} \\
\hline
\end{tabular}

Durante as discussões no Fórum os alunos apontaram que no texto do estudo de caso não foi definido o porte das aeronaves e que esse era o primeiro passo para que alcançassem a solução conjunta para o problema. Nesse contexto, consideraram fortemente os aspectos ambientais, econômicos e científicos supracitados envolvidos na substituição da gasolina de aviação no abastecimento das aeronaves. Assim sendo, foram indicados os pontos de concordância e discordância no texto dos colegas, em defesa do ponto de vista próprio. Então, CA1 assumiu que a melhor solução para o caso é substituição da gasolina de aviação por biocombustível produzido por meio da cana-de-açúcar. Já CA5 considerou que a substituição da gasolina de aviação por etanol é a melhor solução para o estudo de caso.

Para a avaliação de como se deu a discussão no Fórum do ponto de vista colaborativo, classificamos as mensagens enviadas de acordo com a Taxonomia de Habilidades de Aprendizagem. A exemplo do que foi realizado para o caso Idade do plástico, o gráfico correspondente ao ilustrado na Figura 2, consta no Material Suplementar (Figura 1S).

\section{De galão em galão, a prainha vai para o ralo}

De acordo com os critérios pré-estabelecidos, analisamos as discussões das duplas DG1 (menos participativa) e DG5 (mais participativa). Nesse estudo de caso, os estudantes deveriam indicar qual a melhor solução para diminuir os impactos causados pelo derramamento de petróleo na cidade de Macaé - RJ. Na solução textual inicial e individual dos 4 alunos que resolveram este caso, 2 alunos escolheram como melhor solução o uso de técnicas de contenção, mais especificamente da bomba de sucção Skimmer, que possibilita a reutilização do óleo recuperado e o uso de uma esponja superabsorvente. Nas produções textuais dos estudantes, foram considerados aspectos ambientais, pois os vazamentos de petróleo afetam o habitat marinho, aspectos sociais, uma vez que a população é prejudicada pelo problema, pela falta de locais para o lazer e comprometimento da sua saúde caso tomem banho de água contaminada, e aspectos econômicos, pois um dos estudantes elencou os gastos de implementação do método por ele escolhido.

Na produção textual de 1 aluno o método preventivo foi tido como o melhor para a minimização do problema de derramamento de petróleo unido a um plano desenvolvido pelas agências responsáveis por essa atividade, como a Agência Nacional do Petróleo (ANP), a fim de criar propostas relacionadas à prevenção do vazamento de petróleo. Foram dispostos aspectos ambientais, pois os métodos evitariam que o ecossistema da região fosse atingido, e aspectos econômicos, visto que o petróleo perdido poderia se tornar lucrativo para as empresas responsáveis. O último aluno indicou como melhor solução o uso de técnicas magnéticas que utilizam um detergente especial, focando em aspectos científicos que tratam da aglutinação dos íons ferro adicionados à fórmula do detergente junto à mancha de petróleo, facilitando a sua retirada por indução magnética.

Finalizada a etapa de trabalho individual, as 2 duplas formadas produziram 28 mensagens no Fórum, uma média de 14 mensagens por grupo. A Tabela 6 apresenta para cada dupla como os diversos posicionamentos e abordagens individuais de seus integrantes foram confrontados nos grupos e o total de mensagens produzidas em cada discussão.

Durante as discussões no Fórum, os alunos consideraram fortemente os aspectos ambientais e econômicos supracitados envolvidos nos métodos escolhidos para a minimização do problema de vazamento de petróleo. Além disso, mensuraram a viabilidade técnica dos processos e a eficácia dos mesmos na contenção dos vazamentos, bem como a rapidez de resolução do problema. Dessa forma, foram indicados os pontos de concordância e discordância no texto dos 
Tabela 6. Solução inicial proposta por cada membro dos grupos para o estudo de caso De galão em galão, a prainha vai para o ralo

\begin{tabular}{lccc}
\hline Grupo & \multicolumn{2}{c}{ Soluçães } & $\begin{array}{c}\text { Total de } \\
\text { Mensagens }\end{array}$ \\
\cline { 2 - 3 } Aluno 1 & Aluno 2 & \\
\hline Emprego de técnicas & $\begin{array}{c}\text { Emprego de barreiras de } \\
\text { contenção e bombea- } \\
\text { mento do petróleo } \\
\text { confinado }\end{array}$ & 11 \\
tismo & $\begin{array}{c}\text { Emprego de barreiras de } \\
\text { contenção e bombea- } \\
\text { mento do petróleo } \\
\text { confinado }\end{array}$ & $\begin{array}{c}\text { Emprego de métodos de } \\
\text { prevenção do derrama- } \\
\text { mento de petróleo }\end{array}$ & 17 \\
\hline
\end{tabular}

colegas, em defesa do ponto de vista próprio. Assim, DG1 assumiu que a melhor solução para o caso é a contenção mecânica do vazamento aliada à retirada do petróleo derramado por meio da técnica de magnetismo. Já DG5 considerou que a melhor solução combina os métodos de contenção e de remoção e recuperação.

Para a avaliação de como se deu a discussão no Fórum do ponto de vista colaborativo, classificamos as mensagens enviadas de acordo com Taxonomia de Habilidades de Aprendizagem Colaborativa. A exemplo do que foi realizado para o caso Idade do plástico, o gráfico correspondente ao ilustrado na Figura 2, consta no Material Suplementar (Figura 2S).

\section{Socorro, eu não quero alface!}

De acordo com os critérios pré-estabelecidos, analisamos as discussões das duplas SA4 (menos participativa) e SA2 (mais participativa). Nesse estudo de caso, os estudantes deveriam indicar qual o melhor substituto para as gorduras trans presentes em biscoitos artesanais. Na solução textual inicial e individual dos 4 alunos que resolveram este caso, 1 aluno escolheu como melhor solução a substituição da gordura trans por óleo de palma, elencando aspectos relacionados à saúde, pois o óleo de palma é menos prejudicial e aspectos científicos, ligados à não abolição de gorduras da dieta pois elas fornecem 4 vitaminas essenciais ao organismo. Outro aluno indicou como a melhor solução o emprego de diferentes matérias-primas na fabricação dos doces, como meio de diminuição das gorduras trans na receita, evidenciando aspectos relacionados à saúde dos consumidores, assim como citado anteriormente, e aspectos sociais, uma vez que, por ser produtora artesanal, a fabricante dos biscoitos pode não ter acesso à informação sobre os melhores substitutos para a gordura trans.

Outros 2 alunos não indicaram claramente nenhuma solução como sendo a melhor para substituir a gordura trans e foram solicitados a definirem quais soluções iriam defender logo no início do Fórum. No entanto, em suas produções textuais individuais foram vistos aspectos sociais, referentes à conscientização da população acerca dos malefícios da gordura trans, aspectos relacionados à saúde, acerca da substituição por outras gorduras, e aspectos científicos, relacionados à implantação de testes para a averiguação das informações contidas nos rótulos das embalagens. Finalizada a etapa de trabalho individual, as 2 duplas formadas produziram 47 mensagens no Fórum, uma média de 23,5 mensagens por grupo. A Tabela 7 apresenta para cada dupla como os diversos posicionamentos e abordagens individuais de seus integrantes foram confrontados nos grupos e o total de mensagens produzidas em cada discussão.

Durante as discussões no Fórum os alunos consideraram fortemente os aspectos econômicos e relacionados à saúde supracitados, envolvidos na substituição das gorduras trans na fabricação de biscoitos artesanais. Além disso, discutiram sobre a participação
Tabela 7. Solução inicial proposta por cada membro dos grupos para o estudo de caso Socorro, eu não quero alface!

\begin{tabular}{lccc}
\hline Grupo & \multicolumn{2}{c}{ Soluções } & $\begin{array}{c}\text { Total de } \\
\text { Mensagens }\end{array}$ \\
\cline { 2 - 3 } Sluno 1 & Aluno 2 & \\
SA2 & $\begin{array}{c}\text { Substituição da matéria- } \\
\text { prima da fabricação dos } \\
\text { doces por outras livres } \\
\text { de gorduras trans }\end{array}$ & $\begin{array}{c}\text { Substituição da gordura } \\
\text { trans por óleo de palma }\end{array}$ & 13 \\
\hline SA4 & $\begin{array}{c}\text { Não houve posiciona- } \\
\text { mento inicial }\end{array}$ & $\begin{array}{c}\text { Não houve posiciona- } \\
\text { mento inicial }\end{array}$ & 34 \\
\hline
\end{tabular}

governamental na conscientização das pessoas acerca do problema gerado pelo alto consumo das gorduras. Dessa forma, foram indicados os pontos de concordância e discordância no texto dos colegas, em defesa do ponto de vista próprio, por meio de argumentos. Assim, SA2 assumiu que a melhor solução para o caso é a substituição da gordura trans por óleo de palma. Já SA4 considerou que a utilização de matérias-primas livres de gorduras trans é a melhor alternativa para resolver o estudo de caso.

Para a avaliação de como se deu a discussão no Fórum do ponto de vista colaborativo, classificamos as mensagens enviadas de acordo com a Taxonomia de Habilidades de Aprendizagem Colaborativa. A exemplo do que foi realizado para o caso Idade do plástico, o gráfico correspondente ao ilustrado na Figura 2 consta no Material Suplementar (Figura 3S).

Efetividade da colaboração durante a resolução dos estudos de caso: uma análise comparativa

Estudos reportados na literatura apontam que os grupos envolvidos em atividades com o uso da CSCL podem apresentar níveis diferentes de efetividade na colaboração durante a resolução de uma atividade. Nessa perspectiva, apresentamos um olhar mais atento aos grupos participantes dessa pesquisa, mais especificamente, às duplas analisadas anteriormente. A partir dos dados obtidos durante a discussão no Fórum, é possível verificar o grau de efetividade da colaboração entre os estudantes e outras características, como o seu empenho em ajudar o colega a compreender o assunto tratado. Inicialmente, calculamos a frequência na qual as sub-habilidades Conflito Criativo, Aprendizagem Ativa e Conversação foram utilizadas pelas 8 duplas nos 4 estudos de caso. A Figura 3 ilustra os percentuais encontrados para as duplas IP1 e IP3, referentes ao caso Idade do plástico.

A Figura 3 mostra que os percentuais encontrados fornecem o perfil das duplas durante as discussões. Tal classificação foi feita para

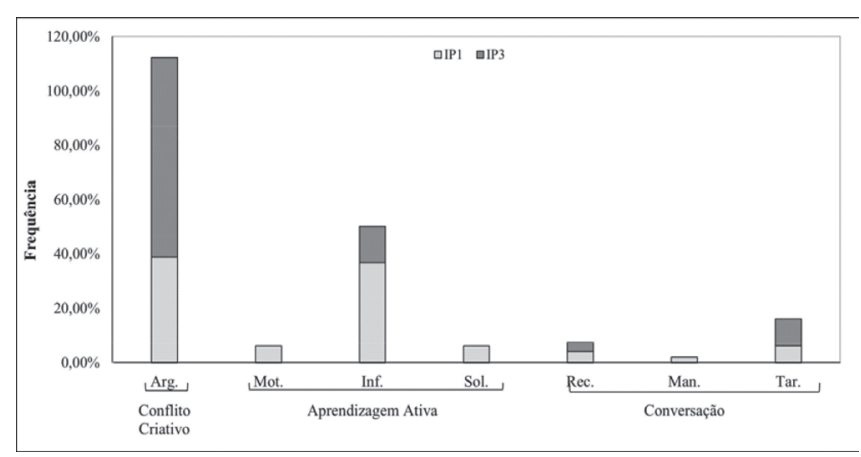

Figura 3. Percentuais das habilidades e sub-habilidades da Taxonomia de Habilidades de Aprendizagem Colaborativa evidenciadas no estudo de caso Idade do plástico. Arg. = argumentação; Mot. = motivação $;$ Inf. = informação $;$ Sol. $=$ solicitação $;$ Rec.$=$ reconhecimento $;$ Man. $=$ manutenção $;$ Tar.$=$ tarefa 
todos os estudos de caso. Os estudantes que resolveram o caso Idade do plástico utilizaram durante a discussão no Fórum as habilidades de Conflito Criativo, Aprendizagem Ativa e Conversação de formas distintas. Em relação ao Conflito Criativo, a dupla IP1 apresentou um percentual de mensagens classificadas de $38,78 \%$ enquanto IP3 se destacou com um percentual de $73,35 \%$. Já em relação à Aprendizagem Ativa, IP1 se destacou com 48,98\% de mensagens classificadas, enquanto IP3 apresentou 13,35\%. Em relação à Conversação, as duplas se mostraram mais equilibradas, sendo que IP1 apresentou um percentual de mensagens classificadas de 12,24\%, enquanto IP3 apresentou o percentual de 13,30\%.

Dessa forma, IP1 concentrou suas mensagens na habilidade de Aprendizagem Ativa enquanto IP3 concentrou suas mensagens na habilidade de Conflito Criativo, o que indica que IP1 apresentou aprendizagem colaborativa mais efetiva do que IP3, segundo Soller et al. ${ }^{6}$

Em relação às sub-habilidades, as duplas utilizaram na maior parte da discussão as de Argumentação e Informação. Porém, os percentuais para cada dupla em cada uma das sub-habilidades foram bastante distintos, o que nos remete ao comportamento das mesmas. A dupla IP1 desempenhou quase o mesmo percentual para as 2 sub-habilidades, como visto na Figura 3, enquanto IP3 concentrou a maior parte de suas mensagens na sub-habilidade de Argumentação. O maior uso de tais sub-habilidades demonstra que os estudantes deram um ao outro a oportunidade de defender a sua solução e apresentar novas informações durante a discussão para a resolução do estudo de caso.

Conforme o ocorrido na discussão de IP1 e IP3, as habilidades de Conflito Criativo, Aprendizagem Ativa e Conversação foram observadas para os casos Cana-de-açúcar pelos ares e De galão em galão, a prainha vai para o ralo, conforme ilustra a Figura 4. As duplas também concentraram sua discussão nas sub-habilidades de Argumentação e Informação.

A Figura 4 ilustra os percentuais encontrados para o caso Canade-açúcar pelos ares (superior) e De galão em galão, a prainha vai para o ralo (inferior).

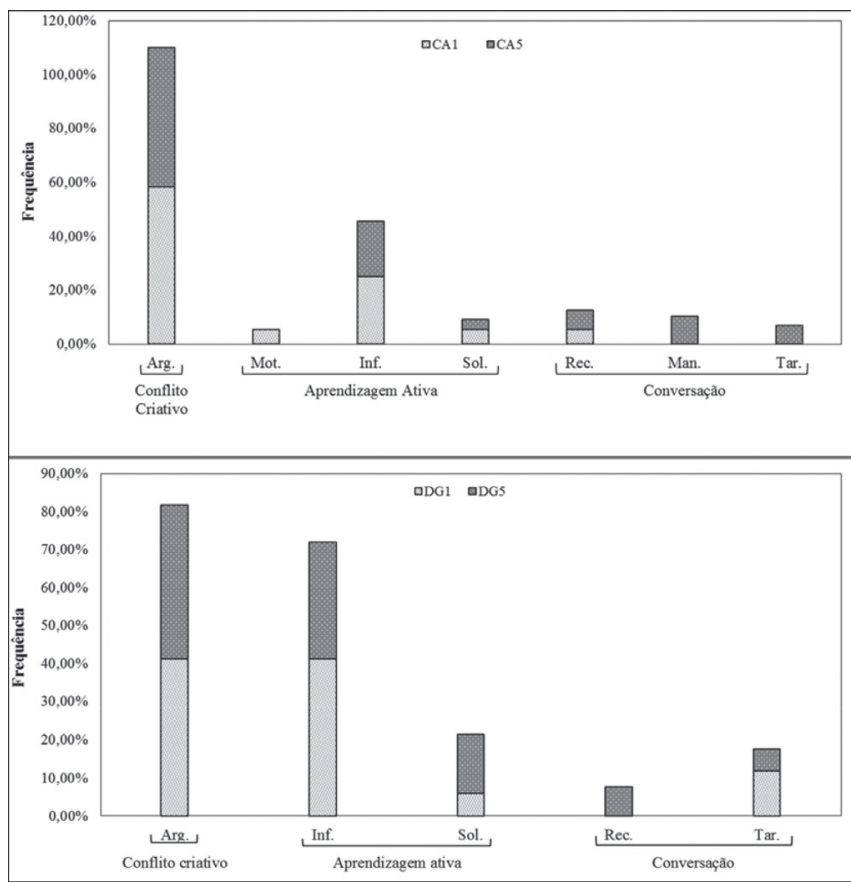

Figura 4. Percentuais das habilidades e sub-habilidades da Taxonomia de Habilidades de Aprendizagem Colaborativa evidenciadas nos estudos de caso Cana-de-açúcar pelos ares (CA) e De galão em galão, a prainha vai para o ralo $(D G)$. Arg. = argumentação; Mot. = motivação Inf. = informação, Sol. $=$ solicitação $;$ Rec.$=$ reconhecimento $;$ Tar.$=$ tarefa
A Figura 4 mostra que os estudantes que resolveram o caso Cana-de-açúcar pelos ares utilizaram durante a discussão no Fórum as habilidades de Conflito Criativo, Aprendizagem Ativa e Conversação de formas distintas. Em relação ao Conflito Criativo, a dupla CA1 apresentou um percentual de mensagens classificadas de 58,35\%, enquanto CA5 se destacou com um percentual de 51,71\%. Já em relação à Aprendizagem Ativa, CA1 apresentou um percentual de $36,10 \%$ de mensagens classificadas, enquanto CA5 apresentou um percentual de $24,15 \%$. Em relação à Conversação, as duplas se mostraram mais desequilibradas, sendo que CA1 apresentou um percentual de mensagens classificadas de 5,55\%, enquanto CA5 apresentou o percentual de $24,14 \%$.

Já para os estudantes que resolveram o caso De galão em galão, a prainha vai para o ralo, conforme ilustra a Figura 4, em relação ao Conflito Criativo, a dupla DG1 apresentou um percentual de mensagens classificadas de 41,18\% enquanto DG5 apresentou um percentual de 40,40\%. Em relação à Aprendizagem Ativa, DG1 apresentou um percentual de $47,06 \%$ de mensagens classificadas, enquanto DG5 apresentou um percentual de $46,14 \%$. Em relação à Conversação, DG1 apresentou um percentual de mensagens classificadas de apenas $11,76 \%$, enquanto DG5 apresentou o percentual de $13,46 \%$.

As duplas CA1 e CA5, assim como a dupla IP3, concentraram suas mensagens na habilidade de Conflito Criativo, o que indica a presença de forte caráter argumentativo na discussão. Da mesma forma que a dupla IP1, as duplas DG1 e DG5 concentraram suas mensagens na habilidade de Aprendizagem Ativa, o que remete a uma colaboração mais efetiva do que IP3, CA1 e CA5, segundo Soller et al. ${ }^{6}$

Em relação às sub-habilidades, assim como ocorrido no caso Idade do plástico, as duplas utilizaram na maior parte da discussão as de Argumentação e Informação. A Figura 4 mostra que as duplas DG1 e DG5 atingiram quase o mesmo percentual para as sub-habilidade Argumentação, enquanto na Informação o percentual de DG1 foi mais elevado. Já as duplas CA1 e CA5 apresentaram quase o mesmo percentual para a sub-habilidades Argumentação e Informação, como visto na Figura 4.

Nessa perspectiva, para os 3 estudos de caso analisados, embora as sub-habilidades de Argumentação e Informação tenham tido destaque durante a atividade, observamos que cada dupla utilizou ao menos mais 3 sub-habilidades, o que demonstra que nas discussões os membros se revezaram no desempenho de papéis, de forma a ampliar o entendimento mútuo, segundo indica o Modelo de Aprendizagem Colaborativa. $^{6}$

Conforme o ocorrido na discussão das duplas anteriormente citadas, as habilidades de Conflito Criativo, Aprendizagem Ativa e Conversação foram observadas para o caso Socorro, eu não quero alface! (Figura 5). De modo distinto do evidenciado anteriormente, o caso foi o único no qual as duplas demonstraram uma incidência de mensagens expressiva na sub-habilidade Solicitação, como ilustra a Figura 5.

Os estudantes que resolveram o caso Socorro, eu não quero alface! utilizaram durante a discussão no Fórum as habilidades de Conflito Criativo, Aprendizagem Ativa e Conversação de formas distintas. Em relação ao Conflito Criativo, a dupla SA2 apresentou um percentual de mensagens classificadas de $36,00 \%$ enquanto SA4 apresentou um percentual de $13,72 \%$. Já em relação a Aprendizagem Ativa, SA4 se destacou com 52,93\% de mensagens classificadas, enquanto SA2 apresentou 40,00\%. Em relação à Conversação, SA2 apresentou um percentual de mensagens classificadas de $24,00 \%$, enquanto SA4 apresentou o percentual de $33,35 \%$.

Tanto SA2 quanto SA4 concentraram suas mensagens na habilidade de Aprendizagem Ativa, porém, SA4 apresentou um maior percentual de mensagens classificadas e aprendizagem colaborativa mais efetiva do que SA2, segundo Soller et al. ${ }^{6}$ 


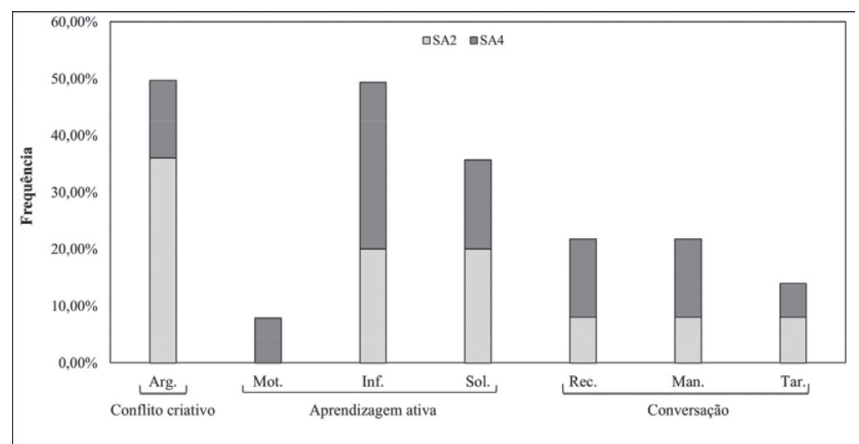

Figura 5. Percentuais de cada habilidade e sub-habilidade relacionadas à Taxonomia de Habilidades de Aprendizagem Colaborativa para o estudo de caso Socorro, eu não quero alface! Arg. = argumentação; Mot. = motivação; Inf. $=$ informação; Sol. $=$ solicitação $;$ Rec. $=$ reconhecimento; Man. $=$ manutenção; Tar. $=$ tarefa

Em relação às sub-habilidades, de maneira distinta do ocorrido para os primeiros 3 casos, SA2 e SA4 utilizaram na maior parte da discussão as habilidades de Argumentação, Informação e Solicitação. A Figura 5 mostra que as duplas desempenharam percentuais distintos para as 3 sub-habilidades, com variações de pelo menos 4 pontos percentuais.

Assim como nos outros 3 estudos de caso, as duplas que solucionaram o caso Socorro, eu não quero alface! utilizaram outras sub-habilidades ao longo da discussão no Fórum, o que confirma que a interação ocorreu de forma a ampliar o entendimento mútuo dos estudantes, conforme indica o Modelo de Aprendizagem Colaborativa. ${ }^{6}$

A partir do exposto, a Figura 6 ilustra para os 4 estudos de caso o percentual de mensagens classificadas nas 3 habilidades referentes à Taxonomia de Habilidades de Aprendizagem Colaborativa.

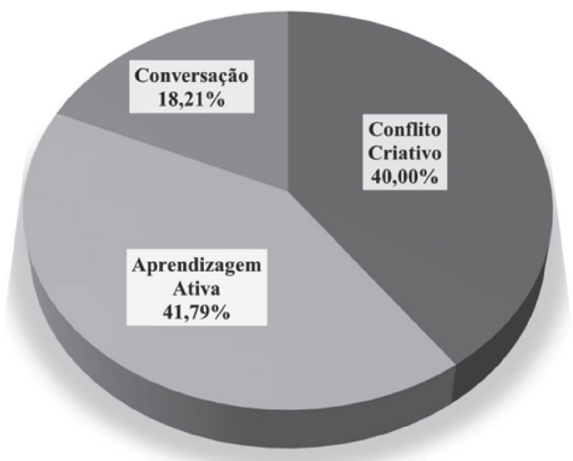

Figura 6. Frequência de mensagens classificadas nas habilidades da Taxonomia de Habilidades de Aprendizagem Colaborativa

Na Figura 6, as habilidades de Conflito Criativo e Aprendizagem Ativa se destacaram durante a resolução dos estudos de caso pelas 8 duplas.

Verificamos que as maiores frequências foram referentes às sub-habilidades Argumentação, pertencente à habilidade de Conflito Criativo, utilizada 112 vezes, o que corresponde a $40 \%$ do total e Informação, pertencente à habilidade de Aprendizagem Ativa, utilizada 80 vezes, o que corresponde a $42 \%$ do total. Estes números evidenciam que, conforme o esperado para os grupos que colaboram de forma mais efetiva, segundo o trabalho de Soller et $a l .{ }^{6}$ os estudantes concentraram um maior número de mensagens na habilidade de Aprendizagem Ativa, seguida da habilidade de Conflito Criativo.

Acreditamos que, além das atividades terem estimulado os estudantes a discutirem de forma colaborativa para solucionar o estudo de caso, a alta incidência de mensagens classificadas na sub-habilidade Argumentação confirma a potencialidade das atividades na promoção dessa habilidade. De fato, isso não é surpreendente, visto que diversos trabalhos ${ }^{8-10}$ demonstram que as atividades que contemplam a resolução de estudos de caso são potencialmente promotoras da argumentação.

\section{CONCLUSÃO}

As Habilidades de Comunicação foram analisadas de forma que as mensagens trocadas entre os estudantes durante a discussão para a resolução do estudo de caso na ferramenta Fórum foram classificadas seguindo a Taxonomia de Habilidades de Aprendizagem Colaborativa. Para o estudo de caso Idade do plástico, as duplas apresentaram 2 soluções distintas, de forma que a mais participativa teve a aprendizagem colaborativa mais efetiva do que a menos participativa, pois apresentou maior percentual de mensagens classificadas na habilidade de Aprendizagem Ativa, conforme critérios estabelecidos pelo Modelo de Aprendizagem Colaborativa. ${ }^{6}$ Os perfis das duplas mostram que as habilidades mais recorrentes durante as discussões foram a Argumentação e a Informação, porém, em intensidades diferentes, o que conferiu à dupla mais participativa uma vantagem em relação à aprendizagem colaborativa.

Para o estudo de caso Cana-de-açúcar pelos ares, as duplas apresentaram 2 soluções distintas, de forma que ambas concentraram a maior parte de suas mensagens na habilidade de Conflito Criativo, o que demonstra que as discussões não foram em sua maior parte efetivas em relação à aprendizagem colaborativa. Contudo, comparando os resultados para a habilidade de Aprendizagem Ativa, a dupla mais participativa apresentou aprendizagem colaborativa mais efetiva do que a menos participativa. Os perfis das duplas mostram que as habilidades mais recorrentes durante as discussões foram a Argumentação e a Informação, porém, em intensidades diferentes, o que conferiu à dupla mais participativa uma vantagem em relação à aprendizagem colaborativa.

Para o estudo de caso De galão em galão, a prainha vai para o ralo, as duplas apresentaram 2 soluções distintas, de forma que ambas concentraram suas mensagens na habilidade de Aprendizagem Ativa, o que demonstra efetividade em relação à aprendizagem colaborativa, conforme o Modelo de Aprendizagem Colaborativa. ${ }^{6}$ Houve equilíbrio entre as duplas, visto que os percentuais de mensagens classificadas apresentaram uma variação mínima na análise de todas as habilidades. Ainda assim, a dupla menos participativa pode ser considerada com aprendizagem colaborativa mais efetiva do que a mais participativa. Os perfis das duplas mostram que as habilidades mais recorrentes durante as discussões foram a Argumentação e a Informação, porém, em intensidades diferentes, o que conferiu uma ligeira vantagem à dupla menos participativa em relação à aprendizagem colaborativa.

Para o estudo de caso Socorro, eu não quero alface!, as duplas apresentaram 2 soluções distintas, de forma que ambas concentraram suas mensagens na habilidade de Aprendizagem Ativa, assim como ocorrido no caso De galão em galão, a prainha vai para o ralo, o que indica efetividade na aprendizagem colaborativa, conforme o Modelo de Aprendizagem Colaborativa. ${ }^{6} \mathrm{~A}$ dupla mais participativa apresentou mais da metade de suas mensagens classificadas nessa habilidade e pode ser considerada mais efetiva do que a menos participativa na aprendizagem colaborativa. Os perfis das duplas mostram, diferente do ocorrido nos demais casos, que as habilidades mais recorrentes durante as discussões foram a Argumentação, Informação e Solicitação, porém, em intensidades diferentes, o que conferiu uma vantagem à dupla mais participativa em relação à aprendizagem colaborativa. 
Conforme já mencionado, a argumentação foi recorrente durante as discussões, o que pode ser confirmado pelos perfis das duplas apresentados anteriormente. Mesmo esta pesquisa não estando desprovida de limitações, como o restrito número de sujeitos pesquisados, concluímos que tal resultado sugere a potencialidade das atividades na promoção dessa habilidade.

\section{MATERIAL SUPLEMENTAR}

Os gráficos referentes à classificação das mensagens dos casos DG, CA e SA segundo a Taxonomia de Habilidades de Aprendizagem Colaborativa, bem como os textos dos 4 estudos de caso utilizados na aplicação da atividade didática estão disponíveis em http://quimicanova.sbq.org.br, na forma de arquivo PDF, com acesso livre.

\section{AGRADECIMENTOS}

À FAPESP (Processo: 12/05437-5), CNPq (Processo: 301936/2012-9) e CAPES pelo apoio financeiro.

\section{REFERÊNCIAS}

1. Stahl, G.; Global Instruction to CSCL, $15^{\text {th }}$ ed., Gerry Stahl: United States, 2015.

2. Ludvigsen, S. R.; Morch, A. I.; The International Encyclopedia of Education, Elsevier: Amsterdam, 2010.

3. Jeong, H.; Hmelo-Slver, C. E.; Yu, Y.; International Journal of Computer-Supported Collaborative Learning 2014, 9, 305.

4. Dillenbourg, P.; Järvelä, S.; Fischer, F.; Technology-enhanced learning, Springer-Verlag: Berlin, 2009.

5. Sá, R. R.; Coura-Sobrinho, J.; Anais do $1^{o}$ Seminário Nacional de Educação Profissional Tecnológica, Belo Horizonte, Brasil, 2008.

6. Soller, A.; Goodman, B.; Linton, F.; Gaimari, R.; Proceedings of 4th International Conference on Intelligent Tutoring Systems, San Antonio, USA, 1998.

7. Herreid, C. F.; Prud'homme-Genéreux, A.; Schiller, N. A.; Herreid, K. F.; Wright, C.; J. Coll. Sci. Teach. 2016, 46, 60.

8. Velloso, A. M. S.; Sá, L. P.; Motheo, A. J.; Queiroz, S. L.; Revista Electrónica de Enseñanza de las Ciencias 2009, 8, 593.

9. Souza, N. S.; Queiroz, S. L.; Ensino, Saúde e Ambiente 2014, 7, 1.

10. Sá, L. P.; Kasseboehmer, A. C.; Queiroz, S. L.; Revista Ensaio 2014, 16, 147. 